\title{
Composite Films from Polystyrene with Hydroxyl end Groups and Carbon Nanotubes
}

\author{
Francisco Gabriel Granados-Martínez $z^{a}$, Lada Domratcheva-Lvova ${ }^{a *}$, Nelly Flores-Ramírez $z^{a}$,
}

\author{
Leandro García-González ${ }^{b}$, Luis Zamora-Peredo ${ }^{b}$, María de Lourdes Mondragón-Sánchez ${ }^{c}$
}

\author{
${ }^{a}$ Universidad Michoacana de San Nicolás de Hidalgo, Gral. Francisco J. Múgica, Felicitas del Río, \\ Morelia, Michoacán, 58030, México \\ ${ }^{b}$ Centro de Investigación en Micro y Nanotecnología de la Universidad Veracruzana, Boca del Río, \\ Veracruz, 94294, México \\ 'Instituto Tecnológico de Morelia, Av. Tecnológico 1500, Lomas de Santiaguito, Morelia, Michoacán, \\ 58120, México
}

Received: October 21, 2016; Revised: January 09, 2017; Accepted: January 15, 2017.

\begin{abstract}
Composites from polystyrene with hydroxyl end groups and multiwall carbon nanotubes were fabricated to evaluate their properties. The Carbon Nanotubes (CNTs) were synthetized by chemical vapor deposition technique using ferrocene and benzene as precursors. Polystyrene with hydroxyl end groups was prepared by solution polymerization employing styrene as monomer, 2-mercaptoethanol as chain transfer agent and AIBN as initiator. Thin films were obtained by two methods: pouring into petri dishes and dip-coating slides. CNTs were characterized to identify morphology and characteristic spectroscopic signals. The polystyrene with hydroxyl end groups and composites were analyzed by SEM, FTIR, Raman and UV-vis spectroscopies, Vickers microhardness and electrical resistivity. Raman analysis demonstrated chemical interactions between CNTs and polystyrene. Results showed that resistivity and transparency decreased by increasing CNTs concentrations in composites; transmittance was about $80 \%$ with $0.8 \mathrm{wt} \%$ content of nanotubes. The highest Vickers hardness registered value was at $1.6 \mathrm{wt} \% \mathrm{CNTs}$ concentration.
\end{abstract}

Keywords: carbon nanotubes, composite materials, polystyrene

\section{Introduction}

Nowadays, the carbon nanotubes are widely studied materials due to their exceptional chemical and physical properties ${ }^{1,2}$; by joining them with other materials these extraordinary characteristics can be transferred. Numerous researches look for interactions between carbon nanotubes and polymer matrices; CNTs dispersion into polymer matrices is a good method to provide electrical and enhanced mechanical properties to these macromolecules ${ }^{3,4}$. The Van der Waals forces that usually agglomerate carbon nanotubes present an impediment to spread them into polymers ${ }^{5}$. Successful dispersion of nanotubes into polymers could be achieved through several chemical modification techniques by adding functional groups to $\mathrm{CNTs}^{6,7}$. Common methods to prepare composites from carbon nanotubes and polymers consist of mixing the materials in a solvent that subsequently evaporates. Other authors achieved well results using the melt mixing technique ${ }^{8}$. This method is used in order to accomplish a physical and chemical interaction between the CNTs and the polymers; also were proposed as the most promising route on the preparation of polymer/CNTs composites ${ }^{9}$. Covalent bonding of polymer chains to CNTs plays an

* e-mail: ladamex@yahoo.es important role in research and development on CNT-based materials ${ }^{10}$. Some researches were focus in the effect of pristine and functionalized carbon nanotubes in polystyrene (PS) matrices ${ }^{11}$. A good dispersion of CNTs in PS thin films, produced by solution casting, was achieved by grafting the nanotubes surface with polystyrene chains ${ }^{12}$. Spitalsky et al. remark that the excellent electrical properties of composites containing multiwall carbon nanotubes are promising for the design of low cost polymer composites for numerous future applications ${ }^{13}$.

Spectroscopy techniques, including Raman and Fourier Transform Infrared Spectroscopy (FTIR), are techniques that provide information for material characterization. Raman spectroscopy can identify carbon nanotubes and characterize different interaction types with polymers ${ }^{14}$; also has become one of the main characterization tools for CNTs due to the analysis of material quality, the microscopic structure of the tube and phonon and electron quantum confinement, data that could be acquired by other techniques, however they require time consuming or special sample preparations ${ }^{15}$.

The present research proposes the introduction of hydroxyl groups and the use of shorter chains of polystyrene matrices to form composites with carbon nanotubes. The CNTs were synthesized by Chemical Vapor Deposition (CVD) with 
laboratory conditions similar to those described on ${ }^{16}$; the nanotubes were obtained with a specific characteristic, $\mathrm{OH}$ functional group. The matrix modification, using short chains and the addition of $\mathrm{OH}$ functional groups in the polymer, represents a new focus on composite polystyrene synthesis, looking for a better interaction between carbon nanotubes and polymer molecules. The aim of this research was to incorporate CNTs into polystyrene with hydroxyl end group matrices, characterize the materials and evaluate their properties.

\section{Materials and Methods}

CNTs synthesis was performed by chemical vapor deposition into an experimental reactor based on ${ }^{16-18}$. Benzene (99.8\%, Aldrich) and ferrocene (98\%, Aldrich) were used as organic precursors, the second compound acted also as catalyst source. Reaction temperature was $760^{\circ} \mathrm{C}$; time process was 1 hour with $80 \mathrm{ml} / \mathrm{min}$ constant argon flow. Polystyrene with hydroxyl end groups (PSOH) was synthesized by solution polymerization according to Gutierrez et al. ${ }^{19}$, using styrene ( $\geq 99 \%$, Aldrich) as monomer, 2-mercaptoethanol (98\%, Aldrich) as chain transfer agent and azobisisobutyronitrile (98\%, Aldrich) as initiator. The polymerization took place under nitrogen atmosphere for 4 hours, with magnetic stirring at $450 \mathrm{rpm}$ and $60{ }^{\circ} \mathrm{C}$; this temperature value was applied to obtain short chain lengths.

Composites from PSOH and CNTs were obtained by mixing both materials inside a flask. The PSOH mixture with $0.2,0.4,0.6,0.8,1.6$ and $3.2 \mathrm{wt} \%$ nanotubes concentrations were stirred at $1200 \mathrm{rpm}$ during $20 \mathrm{~min}$ and settled in an ultrasonic cleaner (Branson 1510) afterwards. Two methods to produce composite films were used. For the first technique the slurry was poured into petri dishes and vacuum dried inside an Isotemp Vacuum Oven (282A) in order to obtain 100 $\mu \mathrm{m}$ thickness films. The second method to produce thinner composites films $(<5 \mu \mathrm{m})$ was using a digital immersion apparatus (E-ANT1; SK-UV). Slides were dipped at $20 \mathrm{~cm} /$ min for 5 seconds in the mixture.

In order to describe morphology of carbon nanotubes, Field Emission Scanning Electron Microscopy (FESEM) in a JEOL 7600 were performed. Scanning Electron Microscopy (SEM) in a JEOL JSM-IT300 characterized the polymer and the composites, the samples were coated with gold using a Denton vacuum sputter coater.

CNTs, PSOH and composites were analyzed by Fourier Transform Infrared Spectroscopy in a Tensor 27 Bruker. Raman Spectroscopy of nanotubes and PSOH were carried out in a MicroRaman DXR Thermo Scientific (solid state laser $532 \mathrm{~nm}$ with 30 samples exposures). An Ultraviolet - Visible spectroscope Mprobe UV-visNIR Semiconsoft examined the PSOH and composites; to perform the observation the films were placed without previously preparation upon a base to analyze thin films.
To acquire the material resistance, the composites were cut to form $0.5 \mathrm{~cm}^{2}$ rectangular areas $(1 \mathrm{~cm} \times 0.5 \mathrm{~cm})$ and the measurements were taken positioning the tip at the shorter length with a Multitester Steren - Mul600. PSOH and all composites concentrations were indented, 4 times by charge, with $0.001,0.003,0.005,0.01$ and $0.025 \mathrm{kgf}$ forces by a Mitutoyo Micro Vickers Hardness Tester.

\section{Results and Discussion}

\subsection{CNTS}

FESEM micrographs showed carbon nanotubes blocks with diameters around $60 \mathrm{~nm}$ and lengths up to $40 \mu \mathrm{m}$ (Figure 1a and b). The EDS analysis demonstrated that the carbon content in atomic percentages were 97.4, oxygen 2.3 and iron $0.3 \%$. The oxygen percentages could be explained by the presence of $\mathrm{OH}$ functional groups on MWCNTs corroborated by FTIR.

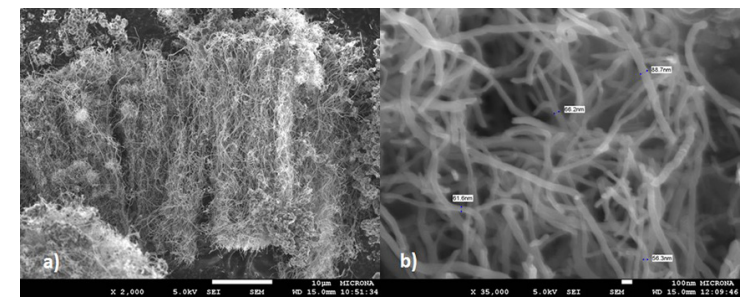

Figure 1. FESEM Micrographs: a) CNTs blocks, b) CNTs diameters.

CNTs FTIR spectra signals (Figure 2a) at $3051 \mathrm{~cm}^{-1}$ correspond to the $\mathrm{CH}_{2}$ stretch in aromatic rings ${ }^{20}$, around $2890 \mathrm{~cm}^{-1}$ to $\mathrm{CH}_{2}$ and $\mathrm{CH}_{3}$ vibrations, common to CNTs obtained by $\mathrm{CVD}^{21,22}$. Bands on the $1750-1550 \mathrm{~cm}^{-1}$ region have been assigned to $\mathrm{C}=\mathrm{C}$ in aromatic rings ${ }^{23}$. Furthermore the typical CNTs signals, the intensity that corresponds to $\mathrm{OH}$ functional group around $3500 \mathrm{~cm}^{-1}$ was found.

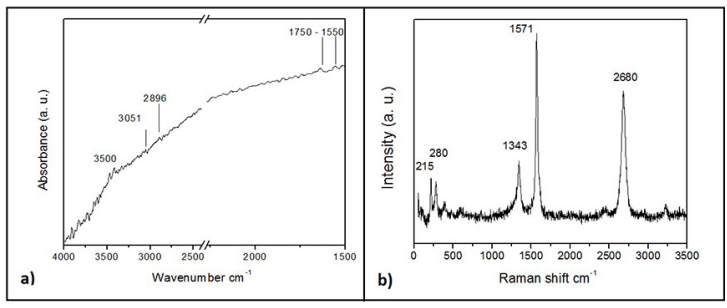

Figure 2. CNTs spectra: a) FTIR, b) Raman.

The Raman spectra (Figure 2b) confirmed CNTs characteristic bands for Multiwall Carbon Nanotubes (MWCNTS). G band reported for graphite like materials at $1571 \mathrm{~cm}^{-1}$, D band assigned to defects in carbon nanotubes at $1343 \mathrm{~cm}^{-1}$ and the $\mathrm{G}^{\prime}$ band, at $2680 \mathrm{~cm}^{-1}$, assented to the first overtone of D mode ${ }^{24-26}$. Belin and Epron ${ }^{24}$ reported 
that the signals around $200 \mathrm{~cm}^{-1}$ correspond to the radial breathing mode of single wall carbon nanotubes, suggesting also their presence, however the D band width indicates that the principal structures are MWCNTs. The ID/IG ratio was 0.31 , this result allows comparing the structural defects in MWCNTs and a higher relation suggests imperfections on the structure, related to $\mathrm{sp}^{3}$ hybridizations $\mathrm{s}^{27,28}$.

\subsection{PSOH and Composites}

SEM images of PSOH and composites are shown in Figure 3. The micrographs showed a uniform polymer surface (Figure 3a). A subsequent analysis of composites demonstrated that despite the CNTs concentration increase, no carbon nanotube presence was observed on their surfaces, upper and lower ends. Figure $3 b$ showed a covering surface of the composite, MWCNTs are focused, a similar picture was observed from the other side, demonstrating that the CNTs were dispersed inside the composites, like a natural sandwich structure. This behavior could be related to the affinity of the matrix and filler materials.

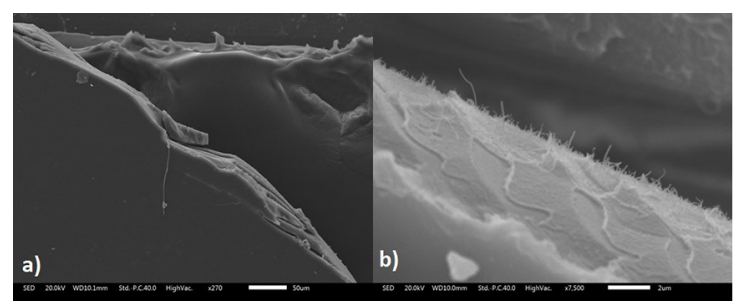

Figure 3. SEM micrographs: a) polymer surface, b) sandwich arrangement.

FTIR spectra of polystyrene with hydroxyl end groups and composites are depicted in Figure 4a. The 3077, 3058 and $3026 \mathrm{~cm}^{-1}$ bands correspond to $\mathrm{C}-\mathrm{H}$ vibrations in aromatic rings. Asymmetric and symmetric tensions of $\mathrm{CH}_{2}$ were observed at 2923 and $2850 \mathrm{~cm}^{-1}$. The 2000-1672 $\mathrm{cm}^{-1}$ region corresponds to the aromatic monosubstituted ring overtone bands. The signals at 1601 and $1493 \mathrm{~cm}^{-1}$ were assigned to aromatic $\mathrm{C}=\mathrm{C}$ stretching. These bands are characteristic to conventional polystyrene ${ }^{29-31}$. Additionally the spectra showed a broad band at $3462 \mathrm{~cm}^{-1}$ due to $\mathrm{OH}$ interactions ${ }^{19,20}$. FTIR composites spectra, from 0.2 to 0.8 CNTs wt $\%$ concentrations (Figure $4 \mathrm{a}$ ), did not show band displacements of polystyrene with hydroxyl end groups. However interactions in the composites could be present. Hoult et al. suggest that the change of absorption intensities is related to films thickness variations ${ }^{32}$.

Figure $4 \mathrm{~b}$ shows the UV-vis spectra for PSOH and 0.8 , 3.2 CNTs wt \% PSOH composites. Similar transmittance values, near $80 \%$, were obtained from polystyrene with hydroxyl end groups and PSOH composites with 0.8 CNTs wt $\%$. A $40 \%$ transmittance value was reached with the highest CNTs concentration composite. Increasing CNTs

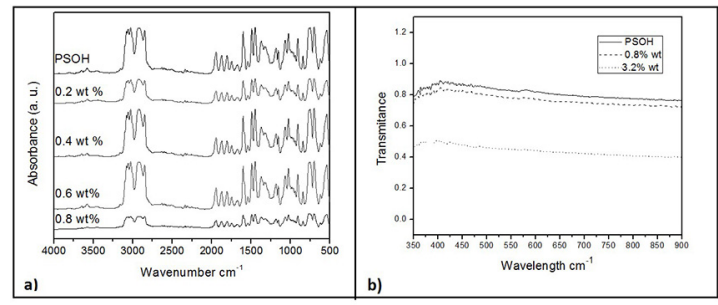

Figure 4. PSOH and composites spectra: a) FTIR, b) UV-vis.

concentration in PSOH composites, transparency decreases. Liu et al. have mentioned the effect on materials optical properties by CNTs concentrations and film preparations ${ }^{33}$. The transmittance value is related to transparency on the films, a constant behavior through several wavelengths (350- $900 \mathrm{~nm})$ can open the door to multiple applications for these composite films.

The pristine PSOH Raman spectra (Figure 5a) show a strong and sharp peak at $1000 \mathrm{~cm}^{-1}$, assigned to the ring breathing mode. The signal around $1300 \mathrm{~cm}^{-1}$ corresponds to the benzene trigonal deformation. The intensities corresponding to the $\mathrm{CH}$ stretching and to $\mathrm{C}-\mathrm{C}$ stretching mode in aromatic rings were located at $1602 \mathrm{~cm}^{-1}$ and $3052 \mathrm{~cm}^{-1}$ respectively ${ }^{34,35}$.

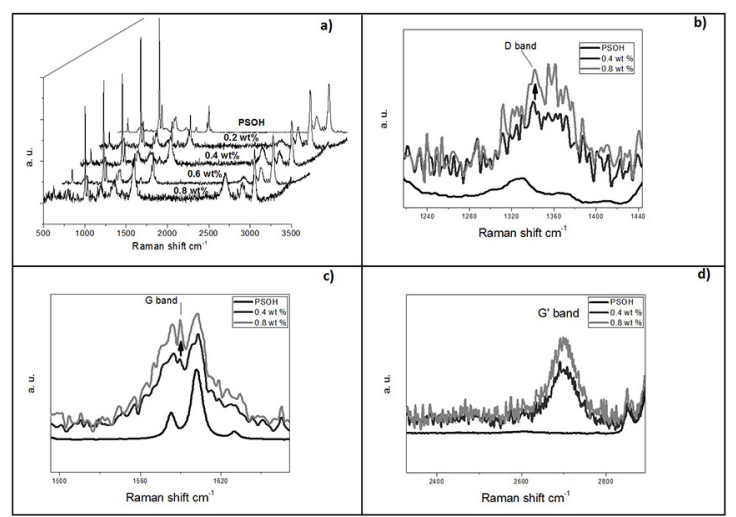

Figure 5. Raman spectra: a) PSOH and composites, b) D band appearance, c) G band appearance and displacement, d) G' band appearance and displacement.

The composites Raman (Figure 5a) spectra have similar appearance to the previously described; notwithstanding, the CNTs incorporated added and displaced some of the signals. The intensity around $1589 \mathrm{~cm}^{-1}$, that correspond to the $\mathrm{G}$ band on carbon nanotubes (Figure 5c), appeared and showed a displacement of $18 \mathrm{~cm}^{-1}$ in comparison to the pristine CNTs. The D band intensity emerged and increased for the composites as is shown in Figure 5b, these behaviors are related to the introduction of covalently bound moieties on the CNTs framework ${ }^{36}$. The D band intensity for the higher concentration were found at $1343 \mathrm{~cm}^{-1}$ and two signals $\left(1355 \mathrm{~cm}^{-1}\right.$ and $\left.1361 \mathrm{~cm}^{-1}\right)$ with higher intensities appeared, originated from an intervalley double resonance 


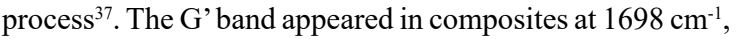
presenting the same displacement that $\mathrm{G}$ band (Figure $5 \mathrm{~d}$ ). The enhanced ID/IG ratio (0.49), found on the composites spectra, in comparison to the pristine carbon nanotubes suggest higher structural defects ${ }^{27}$; thus is indicative of possible CNTs covalent bonding with polymer through interactions between $\mathrm{OH}$ functional groups of the multiwall carbon nanotubes and the $\mathrm{PSOH}^{28}$.

Pristine $\mathrm{PSOH}$ is an electric insulator; however, the addition of CNTs provided a decrease in resistance to composite films. The resistivity was calculated according to:

$$
\rho=R \frac{S}{l}
$$

where " $R$ " is the electrical resistance (Ohms), " $S$ " is the cross-sectional area $\left(\mathrm{m}^{2}\right)$ and " $l$ " is the composite film length $(\mathrm{m})$. The resistivity composite values with 0.2 to 0.8 CNTs wt $\%$ concentrations were $48.7,12.8,6.3$ and 3.2 $\Omega \bullet \mathrm{m}$, respectively (Figure 6 ). This behavior could be for the contribution of the $\mathrm{sp}^{2}$ carbon-carbon bonds, a higher concentration allows more contact between carbon nanotubes and the current passes more freely. For films with $0.8 \mathrm{CNTs}$ $\mathrm{wt} \%$ the electrical resistance was higher than the ones obtained by Jung et al. ${ }^{38}$ with super aligned carbon nanotubes used as transparent heaters.

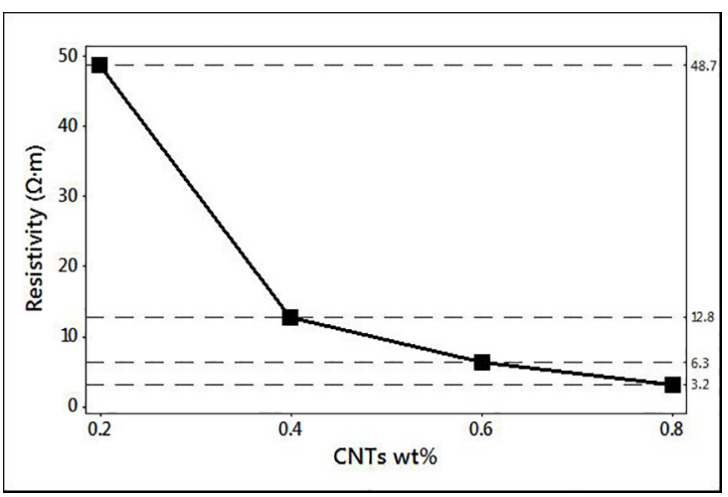

Figure 6. Composites resistivity behavior according to CNTs addition.

Energy dispersion for $0.005 \mathrm{kgf}$ indentation can be appreciated in Figure 7. Several halos were formed with 0.4 CNTs wt $\%$ composite, nevertheless plastic deformation energy was better dispersed with a 3.2 CNTs wt $\%$ concentration. Data was collected for analysis of variance (ANOVA). Hardness was selected as response variable, composites nanotubes concentration ( $\mathrm{wt} \%$ ) and loads were chosen as factors. Results showed an enhanced hardness through force increments, reaching an average of $30 \mathrm{HV}$ (Figure 8a). Figure $8 \mathrm{~b}$ shows hardness fluctuation in composites at different CNTs concentrations; the highest $\mathrm{HV}$ value was at $1.6 \mathrm{wt} \%$ of carbon nanotubes in composites, demonstrating a similar behavior to Yang et al. that work with CNTs and conventional polystyrene ${ }^{39}$.

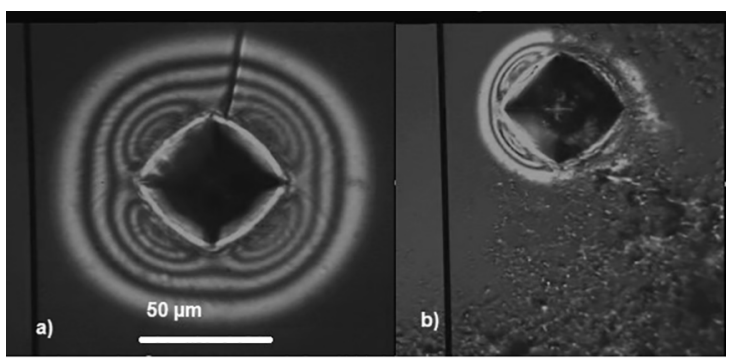

Figure 7. Vickers 0.005 kgf indentation: a) 0.4 CNTs wt $\%$, b) 3.2 CNTs wt $\%$.

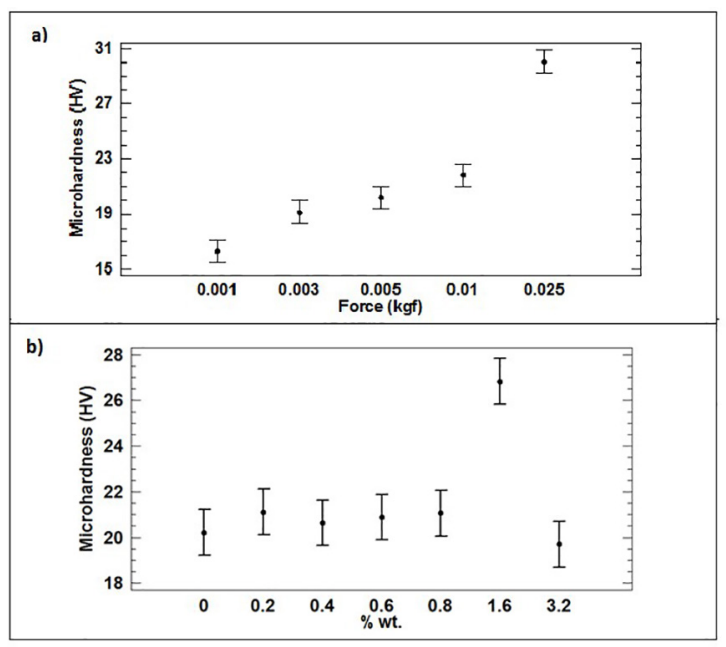

Figure 8. ANOVA results, hardness as response variable, factors: a) force, b) CNTs wt $\%$.

\section{Conclusions}

Thin composite films were obtained through carbon nanotubes and polystyrene with hydroxyl end groups. SEM micrographs showed that CNTs were dispersed inside the composites, like a natural sandwich structure, demonstrating the affinity of the PSOH matrix and carbon nanotubes. Raman analysis demonstrated chemical bonding between MWCNTs and PSOH. The PSOH-CNTs composites mechanical, optical and electrical properties vary with different CNTs concentrations. Carbon nanotubes provided electrical conductivity to the PSOH films. Composite films electrical conductivity was increased depending CNTs percentages addition. The UV-vis spectra indicated a decrease in transparency according to CNTs concentration increase. Optical micrographs of Vickers indentations on composites demonstrated an increment in resistance to deformation with higher CNTs concentration, $1.6 \mathrm{CNTs} w \mathrm{t} \%$ showed the best hardness results. This research represents a new focus producing composites using a short chains polystyrene matrix with $\mathrm{OH}$ functional groups and 
CNTs, with $\mathrm{OH}$ group, to enhance their chemical interaction, opening the door to some future applications.

\section{Acknowledgments}

The authors would like to acknowledge "Universidad Michoacana de San Nicolás de Hidalgo" Scientific Research Coordination, "Nanostructured Materials" Collaboration Network of PRODEP (SEP, Mexico) and to CONACYT doctoral fellowship. We acknowledge to Ph. D. Orlando Hernández and Ph. D. Yesenia Arredondo for SEM analysis, ENES (Morelia) UNAM. This research form part of doctoral thesis in process of M. Sc. Francisco Gabriel Granados directed by Ph. D. Lada Domratcheva and Ph. D. Nelly Flores.

\section{References}

1. De Volder MFL, Tawfick SH, Baughman RH, Hart AJ. Carbon nanotubes: present and future commercial applications. Science. 2013;339(6119):535-539.

2. Aqel A, El-Nour KMMA, Ammar RAA, Al-Warthan A. Carbon nanotubes, science and technology part (I) structure, synthesis and characterisation. Arabian Journal of Chemistry. 2012;5(1):1-23.

3. Kaempgen M, Duesberg GS, Roth S. Transparent carbon nanotube coatings. Applied Surface Science. 2005;252(2):425-429.

4. Mirri F, Ma AWK, Hsu TT, Behabtu N, Eichmann SL, Young $\mathrm{CC}$, et al. High-Performance Carbon Nanotube Transparent Conductive Films by Scalable Dip Coating. ACS Nano. 2012;6(11):9737-9744.

5. Sahoo NG, Rana S, Cho JW, Li L, Chan SH. Polymer nanocomposites based on functionalized carbon nanotubes. Progress in Polymer Science. 2010;35(7):837-867.

6. Ma PC, Siddiqui NA, Marom G, Kim JK. Dispersion and functionalization of carbon nanotubes for polymer-based nanocomposites: A review. Composites Part A: Applied Science and Manufacturing. 2010;41(10):1345-1367.

7. Eitan A, Jiang K, Dukes D, Andrews R, Schadler LS. Surface Modification of Multiwalled Carbon Nanotubes: Toward the Tailoring of the Interface in Polymer Composites. Chemistry of Materials. 2003;15(16):3198-3201.

8. Lu L, Zhou Z, Zhang Y, Wang S, Zhang Y. Reinforcement of styrene-butadiene-styrene tri-block copolymer by multi-walled carbon nanotubes via melt mixing. Carbon. 2007;45(13):26212627.

9. Zhang Z, Zhang J, Chen P, Zhang B, He J, Hu GH. Enhanced interactions between multi-walled carbon nanotubes and polystyrene induced by melt mixing. Carbon. 2006;44(4):692698.

10. Wang C, Guo ZX, Fu S, Wu W, Zhu D. Polymers containing fullerene or carbon nanotube structures. Progress in Polymer Science. 2004;29(11):1079-1141.

11. Yuan JM, Fan ZF, Chen XH, Chen XH, Wu ZJ, He LP. Preparation of polystyrene-multiwalled carbon nanotube composites with individual-dispersed nanotubes and strong interfacial adhesion. Polymer. 2009;50(14):3285-3291.
12. Lin TS, Cheng LY, Hsiao CC, Yang ACM. Percolated network of entangled multi-walled carbon nanotubes dispersed in polystyrene thin films through surface grafting polymerization. Materials Chemistry and Physics. 2005;94(2-3):438-443.

13. Spitalsky Z, Tasis D, Papagelis K, Galiotis C. Carbon nanotubepolymer composites: chemistry, processing, mechanical and electrical properties. Progress in Polymer Science. 2010;35(3):357-401.

14. Rahmat M, Hubert P. Carbon nanotube-polymer interactions in nanocomposites: A review. Composites Science and Technology. 2011;72(1):72-84.

15. Thomsen C, Reich S. Raman Scattering in Carbon Nanotubes. In: Cardona M, Merlin R, eds. Light Scattering in Solid IX. Berlin, Heidelberg: Springer; 2007. p. 115-234.

16. Gómez Sánchez A, González PG, García González L, Granados Martínez FG, Flores Ramírez N, López Garza V, et al. Carbon nanotubes obtained along variations in chemical vapor deposition process for improvement in mechanical properties of an epoxy composite. Journal of Analytical and Applied Pyrolysis. 2015;113:483-490

17. Granados-Martínez FG, Contreras-Navarrete JJ, García-Ruiz DL, Gutiérrez-García CJ, Durán-Navarro A, Gama-Ortega EE, et al. MWCNTs synthesis from butanol, diethyl ether, ethyl acetate and hexane by chemical vapor deposition with a stainless steel core as catalyst. Superficies y Vacio. 2015;28(4):108-110.

18. Granados-Martínez FG, Contreras-Navarrete JJ, García-Ruiz DL, Gutiérrez-García CJ, Durán-Navarro A, Gama-Ortega EE, et al. Carbon Nanotubes Synthesis from Four Different Organic Precursors by CVD. MRS Online Proceedings Library Archive. $2016 ; 1817$.

19. Gutiérrez-Arriaga $\mathrm{O}$, Vásquez-García SR, Flores-Ramírez N, Luna-Bárcenas G, Barrera Cardiel G, León-Patiño CA. A Film of Polystyrene Hydroxyl end Group Supported on $\mathrm{SiO}_{2}$ Monoliths: Thermal Conductivity and Micro-Indentation. Global Journal of Science Frontier Research Chemistry. 2012;12(6B).

20. Pavia DL, Lampman GM, Kriz GS, Vyvyan JA. Introduction to spectroscopy. $4^{\text {th }}$ ed. Boston: Cengage Learning; 2009. p. 43-47.

21. Teng L, Tang T. IR study on surface chemical properties of catalytic grown carbon nanotubes and nanofibers. Journal of Zhejiang University-SCIENCE A. 2008;9(5):720-726.

22. Contreras-Navarrete JJ, Granados-Martínez FG, DomratchevaLvova L, Flores-Ramírez N, Cisneros-Magaña MR. MWCNTs oxidation by thermal treatment with air conditions. Superficies y Vacio. 2015;28(4)111-114.

23. Stobinski L, Lesiak B, Kövér L, Tóth J, Biniak S, Trykowski $\mathrm{G}$, et al. Multiwall carbon nanotubes purification and oxidation by nitric acid studied by the FTIR and electron spectroscopy methods. Journal of Alloys and Compounds. 2010;501(1):77-84.

24. Belin T, Epron F. Characterization methods of carbon nanotubes: a review. Materials Science and Engineering: $B$. 2005;119(2):105-118.

25. Shiratori $Y$, Hiraoka H, Yamamoto M. Vertically aligned carbon nanotubes produced by radio-frequency plasma-enhanced chemical vapor deposition at low temperature and their growth mechanism. Materials Chemistry and Physics. 2004;87(1):31-38. 
26. Delhaes P, Couzi M, Trinquecoste M, Dentzer J, Hamidou H, Vix-Gurtel C. A comparison between Raman spectroscopy and surface characterizations of multiwall carbon nanotubes. Carbon. 2006;44(14):3005-3013.

27. Antunes EF, Lobo AO, Corat EJ, Trava-Airoldi VJ. Influence of diameter in the Raman spectra of aligned multi-walled carbon nanotubes. Carbon. 2007;45(5):913-921.

28. Abdalla M, Dean D, Adibempe D, Nyairo E, Robinson P, Thompson G. The effect of interfacial chemistry on molecular mobility and morphology of multiwalled carbon nanotubes epoxy nanocomposite. Polymer. 2007;48(19):5662-5670.

29. León-Bermúdez AY, Salazar R. Synthesis and characterization of the polystyrene - asphaltene graft copolymer by FT-IR spectroscopy. CT\&F-Ciencia, Tecnología y Futuro. 2008;3(4):157-167.

30. Jaleh B, Madad MS, Tabrizi MF, Habibi S, Golbedaghi R, Keymanesh MR. UV-degradation effect on optical and surface properties of polystyrene- $\mathrm{TiO}_{2}$ nanocomposite film. Journal of the Iranian Chemical Society. 2011;8(Suppl 1):S161-S168.

31. Kaniappan K, Latha S. Certain investigations on the formulation and characterization of polystyrene, poly (methyl meth acrylate) blends. International Journal of ChemTech Research . 2011;3(2):708-717.

32. Spragg RA, Perston B, Hoult RA. Polystyrene Film as a Standard for Testing FT-IR Spectrometers. Spectroscopy. 2013;28(2):38-43.
33. Liu B, Hsu C, Wang W. A comparative study on preparation of conductive and transparent carbon nanotube thin films. Journal of the Taiwan Institute of Chemical Engineers. 2012;43(1):147-152.

34. Hong PP, Boerio FJ, Clarson SJ, Smith SD. An investigation of the interdiffusion of polystyrene and deuterated polystyrene using surface-enhanced Raman scattering. Macromolecules. 1991;24(17):4770-4776.

35. Granadino-Roldán JM, Fernández-Gómez M, Navarro A. The vibrational analysis of styrene, revisited. Chemical Physics Letters. 2003;372(1-2):255-262.

36. Wang HC, Li Y, Yang MJ. Sensors for organic vapor detection based on composites of carbon nanotubes functionalized with polymers. Sensors and Actuators B: Chemical. 2007;124(2):360367.

37. Fantini C, Pimenta MA, Strano MS. Two-Phonon Combination Raman Modes in Covalently Functionalized Single-Wall Carbon Nanotubes. The Journal of Physical Chemistry C. 2008;112(34):13150-13155.

38. Jung D, Kim D, Lee KH, Overzet LJ, Lee GS. Transparent film heaters using multi-walled carbon nanotube sheets. Sensors and Actuators A: Physical. 2013;199:176-180.

39. Yang Z, Dong B, Huang Y, Liu L, Yan FY, Li HL. Enhanced wear resistance and micro-hardness of polystyrene nanocomposites by carbon nanotubes. Materials Chemistry and Physics. 2005;94(1):109-113. 